Please cite this paper as: Shi, J.; Puig, R.; Sang, J.; Lin, W. A comprehensive evaluation of physical and environmental performances for wet-white leather manufacture. Journal of Cleaner Production 139 (2016) 1512-1519.

\title{
A comprehensive evaluation of physical and environmental performances for wet-white leather manufacture
}

\author{
Jiabo Shi ${ }^{\text {a }}$, Rita Puig ${ }^{b, *}$, Jun Sang ${ }^{a}$, Wei Lin ${ }^{\text {a, }}$ \\ ${ }^{a}$ National Engineering Laboratory for Clean Technology of Leather Manufacture, Key Laboratory of \\ Leather Chemistry and Engineering of Ministry of Education, Sichuan University, Chengdu, 610065, \\ China \\ ${ }^{b}$ Universitat Politècnica de Catalunya, Igualada School of Engineering (EEI), Igualada, Barcelona, Spain
}

\begin{abstract}
This paper presents the comprehensive evaluation results of physical and environmental performances for a novel wet-white (chrome-free) leather manufacturing. The tanning process is optimized as $15 \mathrm{wt} \%$ tannic acid (TA) combination with $4 \mathrm{wt} \%$ Laponite nanoclay, giving the leather with shrinkage temperature $\left(T_{\mathrm{s}}\right)$ above $86^{\circ} \mathrm{C}$. Inductively coupled plasma-atomic emission spectrometry (ICP-AES) measurements indicate that Laponite can be evenly and tightly bound within the leather matrix, which is further confirmed by scanning electron microscopy and energy dispersive X-Ray (SEM-EDX) spectroscopy analysis. The resultant wet-white leathers have reasonable good physical properties that can meet the standard requirements for furniture leather without containing hazardous $\mathrm{Cr}(\mathrm{VI})$ and formaldehyde. Further life cycle assessment (LCA) studies shows that tanning process is the main contributor to environmental impact categories in the wet-white tanning process, and tannic acid is the most significant substance factor. Compared to conventional chrome tanning, the wet-white tanning process exhibits much lower abiotic depletion potential (ADP), and reduced global warming potential (GWP) and human toxicity potential (HTP) impacts due to the nature of vegetable tanning; whereas, GWP excluding biogenic carbon and energy consumption are higher owing to prolonged run time.
\end{abstract}

Keywords: Wet-white leather; Tannic acid; Laponite nanoclay; Combination tannage; Life cycle assessment

\footnotetext{
* Corresponding anthor: Tel: +34 (93) 8035300, Email: rita.puig@ eei.upc.edu

${ }^{\dagger}$ Corresponding anthor: Tel: +86 (28) 85460819, E-mail: wlin@ @scu.edu.cn
} 


\section{Introduction}

In recent decades, increasing issues on the environmental and human health risks have greatly accelerated people's focus on developing more environmental-friendly leather chemicals (Krishnamoorthy et al., 2013) and cleaner technologies for leather manufacturing (Wang et al., 2016). As the decisive procedure during the structural transformation of collagen fibers into leather matrix, tanning process has been widely recognized and studied (Covington, 1997). Its main environmental burdens are originated from the consumptions of tanning materials and the emissions of solid wastes and wastewaters (Zhang et al., 2016).

Currently, chrome tanned leather shares a high proportion of all leather articles worldwide (Covington, 2009). Some of chemicals used in post-tanning procedures can lead to the possible conversions of $\mathrm{Cr}(\mathrm{III})$ to $\mathrm{Cr}(\mathrm{VI})$ (Chandra Babu et al., 2005). The formation of $\mathrm{Cr}(\mathrm{VI})$ can cause severe allergic contact dermatitis in human skins and can elicit dermatitis at very low concentrations (Hansen et al., 2003). In 2014, a more stringent restriction on the $\mathrm{Cr}(\mathrm{VI})$ concentration of leather articles was revised by the European Commission in Annex XVII of regulations of Registration, Evaluation, Authorization and Restriction of Chemicals $(\mathrm{REACH})$. In the new restrictions, leather articles, coming into direct and prolonged or repetitive contact with the skin, should not be placed on the market if they contain $\mathrm{Cr}(\mathrm{VI})$ in concentrations equal to or higher than $3 \mathrm{mg} / \mathrm{kg}$. The restriction and risk of $\mathrm{Cr}(\mathrm{VI})$ have directly affected the production, consumption and circulation of chrome tanned leather articles. Nowadays China is the largest country of leather production in the world. As a dominant traditional manufacture, leather-making industry in China is now faced with counteraction of environmental pollution and green trade barrier in leather exports.

In the case, wet-white (chrome-free) tanning towards Eco-leather manufacture has been increasingly emphasized in order to replace or reduce conventional chrome tanning, like the novel tannage based on nano- $\mathrm{SiO}_{2}$ (Liu et al., 2010), and titanium based tannage (Crudu et al., 
2014), etc. Among these, the combination tannage of vegetable tannin and nano-silicate for wet-white leather manufacture (Shi et al., 2013) has been considered as a promising alternative to conventional chrome tannage due to natural resources and appropriate tanning properties. The developed wet-white tanning system is completely free of chromium and formaldehyde.

On the other hand, environmental assessments of a new tanning process related to human health and environmental risks are also essential for leather manufacturing. Various environmental assessment techniques are involved including materials flow analysis (Brunner and Rechberger, 2004), environmental impact assessment (Jay et al., 2007), multi-objective optimization (Erol and Thöming, 2005) and human health and environmental risk assessment (ERA) (Bridges, 2003). However, these assessment techniques are generally not comprehensive enough (Burgess and Brennan, 2001), and ERA is often more a legal procedure than a detailed environmental assessment tool (Tukker, 2000). Life cycle assessment (LCA) is a specific elaboration of an environmental evaluation framework which differs fundamentally from the above techniques. It is a systematic tool for the identifications, quantifications and evaluations of a product, process or activity, by measuring full range of environmental impacts related to the input and output flows, energy and materials exhaustions and wastes disposal (Guinée, 2002). LCA has been regulated by the ISO 14040 and 14044 since 2006. LCA methodology has been recently applied to quantify and assess environmental impacts of polymer materials (Shen and Patel, 2008), nanomaterials (Pourzahedi and Eckelman, 2015), building materials (Silvestre et al., 2014) and the process industry (Jacquemin et al., 2012), and leather manufacturing. In the newly reported chrome-free tanning process, carbon footprinting calculated by global warming potential (GWP), toxicity indicators and energy consumption have been used for the environmental assessment from LCA perspective; nevertheless, physical performances along with hazardous substances in the 
leather are not involved (Xu et al., 2015).

Recently, we have developed a novel wet-white tannage based on the vegetable tannin in combination with Laponite nanoclay (Shi et al., 2016). The key is to create synergistic effects between inorganic nanoclay and organic tannins by solving the diffusion of tanning substances and their bindings with collagen fibers of hides and skins. In the present work, we further optimize the combination wet-white tanning process by comparative studying the synergistic tanning effect of two typical vegetable tannins with Laponite. We focus on the binding stability of Laponite in crust leather during post-tanning procedures and its influence on the physical performances of the wet-white leathers. The environmental impacts of the novel wet-white tanning have been quantified by LCA method for the first time. Our aim is to obtain a comprehensive evaluation for a new tanning process and the leather product which would enable careful tanning material design to rationalize processes and overcome ecological problems.

\section{Materials and methods}

\subsection{Materials}

$1000 \mathrm{~kg}$ pickled cattle hide were taken as raw materials for leather manufacture. The chemicals used for leather processing were all of commercial grade. The dosages of the chemicals were all based on the weight of pickled pelts. Two typical vegetable tannins, tannic acid (TA, tannins content: $81 \mathrm{wt} \%$ ) and mimosa extracts (tannins content: $72.5 \mathrm{wt} \%$ ) were purchased from Institute of Chemical Industry of Nanjing Forest Products (China) and Seta SUN (Brazil), respectively. Laponite nanoclay, a synthetic disc-shaped nano-silicate consisting of nanoparticles (diameter: $25 \sim 30 \mathrm{~nm}$; thickness: 1 nm) incorporating an organic pyrophosphate peptiser, was purchased from BYK Additives \& Instruments (U.K.). 


\subsection{Leather processing}

Table 1 gives the optimized combination tanning process recipe for wet-white leather according to our previously reported methods (Shi et al., 2016). Specifically, in the de-pickling procedure, the $\mathrm{pH}$ values of pelts are adjusted to 4.5 . And $15 \%$ vegetable tannin and 3\% Laponite are added for $3 \mathrm{~h}$ tanning, with the final $\mathrm{pH}$ of the tanning float adjusted at 3.5. Then the wet-white leather are piled overnight. The tanning recipe for chrome tanned leather is also listed in Table 2 as the control. The pickled pelts are tanned with $8 \%$ chrome powder for $2 \mathrm{~h}$. Then the float are basified to $\mathrm{pH} 3.8 \sim 4.2$ for another $3 \mathrm{~h}$ to complete the tanning for wet-blue.

Shrinkage temperature $\left(T_{\mathrm{s}}\right)$, a measure of hydrothermal stability of the crust leather (Covington, 1997), was determined by a shrinkage tester using the official method (ASTM, 2004). A $10 \mathrm{~mm} \times 60 \mathrm{~mm}$ specimen was cut out from the leather sample and was inserted into the bath of water. Then the bath was heated at a rate such that the rise in temperature was kept at $2{ }^{\circ} \mathrm{C}$ per minute. The temperature at the first definite sign of shrinking was recorded. The experimental plot was obtained from average of three samples.

\section{Table 1}

Process recipe for wet-white leather

\begin{tabular}{lcccc}
\hline Procedures & Chemicals & Amount (\%) & Time (min) & Remarks \\
\hline De-pickling & $\mathrm{H}_{2} \mathrm{O}$ & 100 & & $25^{\circ} \mathrm{C}$ \\
& $\mathrm{NaHCO}_{3}$ & $1 \sim 2$ & 60 & Check pH 4.5 \\
\multirow{4}{*}{ Tanning } & Vegetable tannin & 15 & 240 & \\
& Nanoclay & 3 & 180 & \\
& $\mathrm{HCOOH}$ & $0.3 \sim 0.5$ & 60 & $T_{\mathrm{s}} \geq 85^{\circ} \mathrm{C}$, piled overnight \\
\hline
\end{tabular}




\section{Table 2}

Process recipe for conventional chrome tanned leather

\begin{tabular}{ccccc}
\hline Procedures & Chemicals & Amount $(\%)$ & Time (min) & Remarks \\
\hline Pickling & $\mathrm{H}_{2} \mathrm{O}$ & 100 & & $25^{\circ} \mathrm{C}$ \\
& $\mathrm{NaCl}$ & 8 & 10 & Check pH $2.8 \sim 3.0$ \\
& $\mathrm{H}_{2} \mathrm{SO}_{4}$ & 1.25 & 90 & \\
Tanning & $\begin{array}{c}\text { Chrome } \\
\text { powder } \\
\mathrm{H}_{2} \mathrm{O}\end{array}$ & 8 & 120 & Check the penetration \\
& $\mathrm{NaHCO}_{3}$ & 1.5 & $3 \times 20+120$ & $\begin{array}{c}\text { Check pH } 3.8 \sim 4.2 \text { and } \\
T_{\mathrm{s}} \geq 95{ }^{\circ} \mathrm{C}, \text { piled overnight }\end{array}$ \\
\hline
\end{tabular}

\subsection{ICP-AES measurements}

The content of Laponite in the wet-white crust leather and its residue in tanning floats were monitored with inductively coupled plasma-atomic emission spectrometry (ICP-AES) technique by measuring the $\mathrm{Mg}$ trace as the characteristic element of Laponite (Metreveli et al., 2005). $0.1 \mathrm{~g}$ crust leather samples and $2.0 \mathrm{~mL}$ floats taken from different wet-white tanning procedures were digested by $10 \mathrm{~mL} \mathrm{HCl} / \mathrm{HNO}_{3}$ solution $(\mathrm{v} / \mathrm{v}, 3: 1)$ for $2 \mathrm{~h}$ at $110{ }^{\circ} \mathrm{C}$, respectively. The digested solution was filtered and the filtrate was then diluted with deionized water. $5 \mathrm{~mL}$ analytical solution was used for the measurements of $\mathrm{Mg}^{2+}$ concentration by an ICP-AES spectrometer (Optima 2100DV, Perkin-Elmer, USA) equipped with an auto sampler. The analyte wavelength of $\mathrm{Mg}$ was $285.2 \mathrm{~nm}$. The adsorption capacity and the residue of Laponite were calculated according to its composition and expressed as $\mathrm{mg} / \mathrm{g}$ of the crust and $\mathrm{mg} / \mathrm{L}$ of the float, respectively. The experimental plot was obtained from average of three samples.

\subsection{SEM-EDX analysis}

The samples were taken from the grain, middle and flesh layers of the wet-white crust leather, respectively. After lyophilized at $-43{ }^{\circ} \mathrm{C}$ in a freeze dryer (Alpha 1-2 LD, Christ, 
Germany) for $24 \mathrm{~h}$, the samples were cut into the specimens with a thickness of $1.0 \mathrm{~mm}$ by a microtome (CM1900, Leica, Germany) before the observations. The morphologies of leather specimens were recorded by a scanning electron microscope (JSM-7500F, JEOL, Japan) at an accelerating voltage of $15 \mathrm{kV}$. The relative elemental compositions of the specimens were confirmed by a coupled energy dispersive X-ray spectroscopy (EDX) detector.

\subsection{Physical performance and hazardous substances measurements}

Physical performance measurements of wet-white crust and finished leather were carried out with the approaches recommended by the International Union of Leather Technologists and Chemists Societies (IULTCS). Tensile strength and percentage extension, tear load and resistance to grain cracking of the crust and finished leather were tested using IULTCS/IUP 6 (in accordance with ISO 3376: 2011), IULTCS/IUP 8 (in accordance with ISO 3377-2: 2016) and IULTCS/IUP 12 (in accordance with ISO 3378: 2002), respectively. The standardized chemical methods recommend by the IULTCS were applied for determining hazardous substances in the wet-white crust and finished leather. Moreover, the contents of limited hazardous substances, Cr(VI) and formaldehyde, were measured with IULTCS/IUC 18 (in accordance with ISO 17075: 2007) and IULTCS/IUC 19 (in accordance with ISO 17226-1: 2008), respectively. The experimental plot was obtained from average of three samples.

\subsection{Environmental impacts assessment}

For assessing the environmental impacts of the wet-white tanning process, all inventory and procedures data consisting of the inputs and outputs in the tanning procedures were collected and reviewed with mass balances as well as conventional chrome tanning process. A simplified life cycle assessment (LCA) was applied to quantitatively evaluate the environmental impacts of both tanning processes using the standard ISO 14044 (2006).

System boundaries of the comparative life cycle study are shown in Fig. 1. Life cycle inventory (LCI) of the two tanning processes is detailed considering their chemicals and 
energy consumptions. The inputs and outputs data are depicted in Fig. 2 and Fig. 3, respectively. The study was modeled using GaBi 6 software and the impact categories were evaluated following the CML 2001 methodology (updated in 2013) (Guinée, 2002).

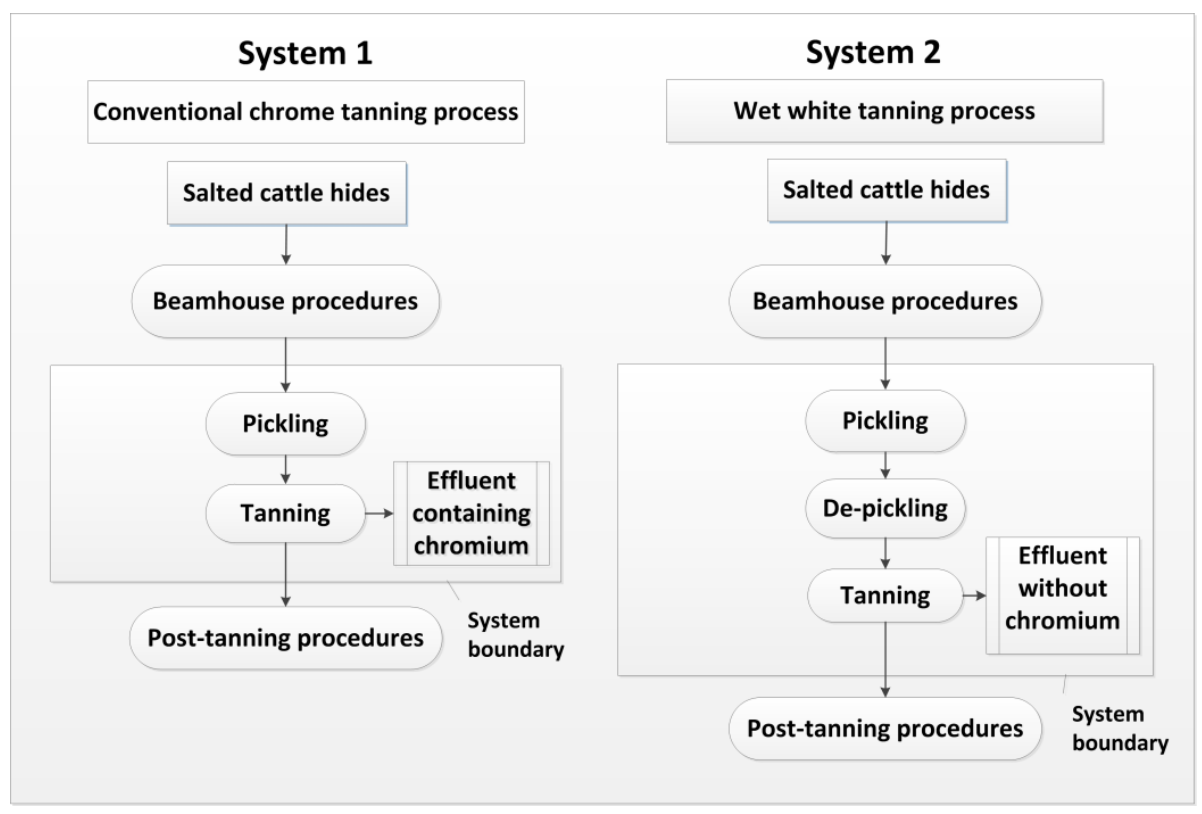

Fig. 1. System boundaries of the comparative life cycle study of conventional chrome tanning process (System 1) and wet-white tanning process (System 2)

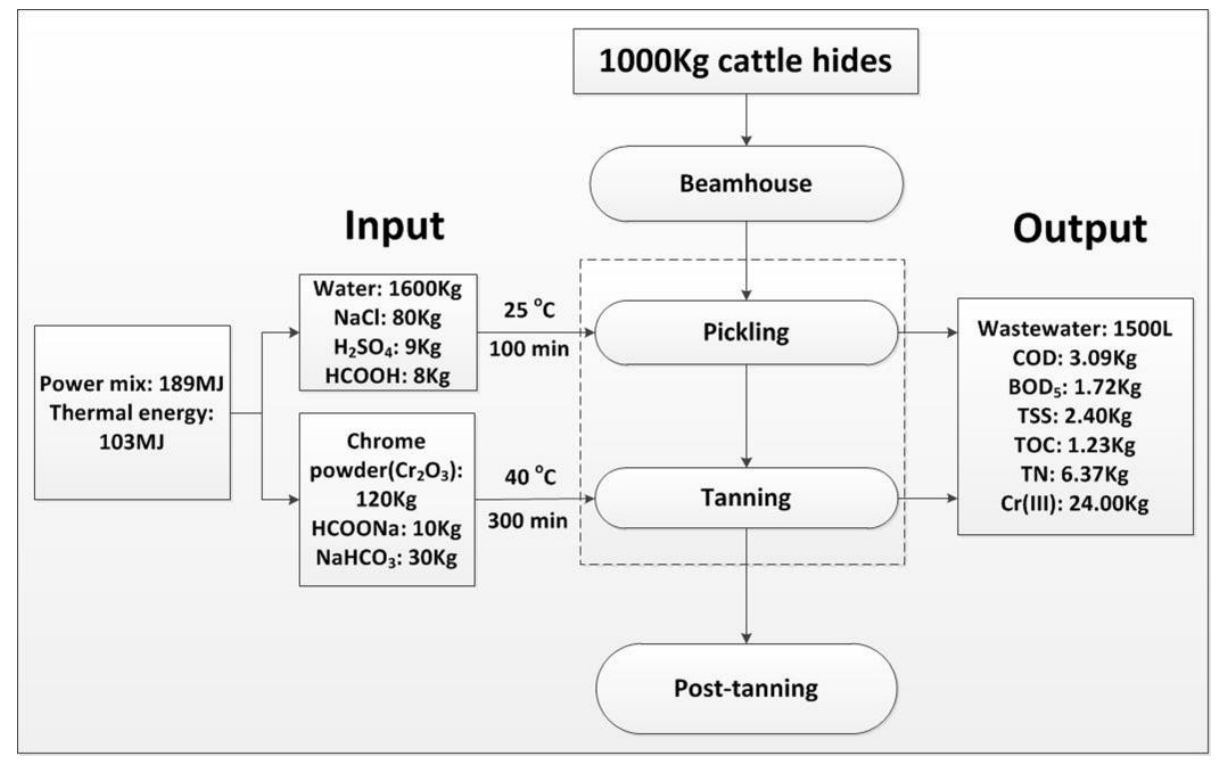

Fig. 2. Flow sheet of chemicals and energy inventory for conventional chrome tanning process 


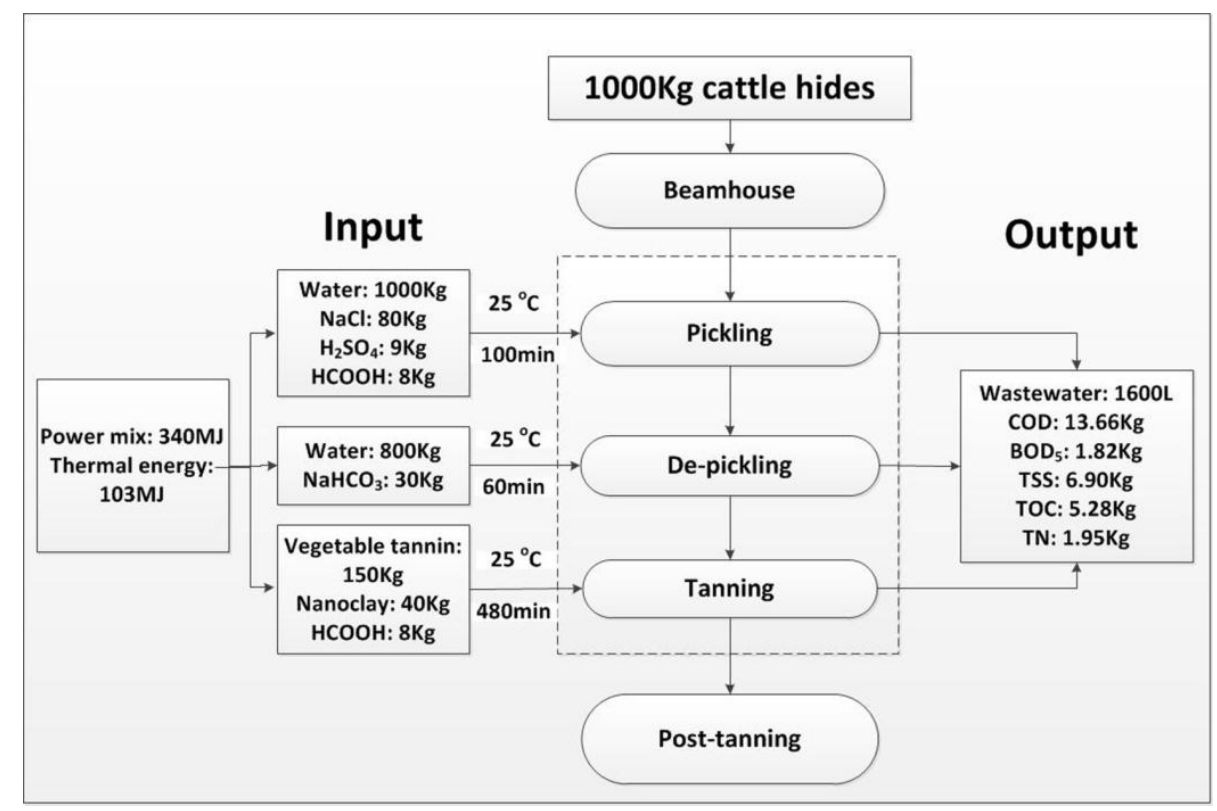

Fig. 3. Flow sheet of chemicals and energy inventory for wet-white tanning process

The model takes into account the electricity and thermal energy production, according to China shared-percentage among different used primary energy sources. Chinese electricity mix and thermal energy mix are not available in GaBi6 database; therefore they were developed from Chinese data for tanning regions. Thus, thermal energy was produced from coal $(72.9 \%)$, gasoline $(8.2 \%)$, diesel oil $(13.3 \%)$ and fuel oil $(5.7 \%)$ and electricity from hydroelectric (17.3\%), coal (79.85\%), nuclear (1.77\%) and wind power plants (1.07\%). And, coal is mainly lignite (79.6\%) and anthracite (20.4\%). Production of chemicals was also considered inside the system boundaries, but due to the lack of some chemicals in GaBi 6 database, the following proxies have been used: acetic acid instead of formic acid and sodium carbonate instead of sodium bicarbonate.

In the case of tannic acid (TA) used in our study, due to lack of data, a similar tannin obtained from patchouli dried leaves in India was considered, which uses ethyl acetate and water as extraction agents. A recycling and re-use of the solvent was also considered in the model. Moreover, Laponite nanoclay was modeled according to its composition in different inorganic components: $\mathrm{SiO}_{2}(54.5 \mathrm{wt} \%), \mathrm{MgO}(26.0 \mathrm{wt} \%), \mathrm{Li}_{2} \mathrm{O}(0.8 \mathrm{wt} \%), \mathrm{Na}_{2} \mathrm{O}(5.6 \mathrm{wt} \%)$ 
and $\mathrm{P}_{2} \mathrm{O}_{5}(4.4 \mathrm{wt} \%)$. Waste water treatment (WWT) was modeled considering energy recovery from organic sludge. Data on the WWT plant was taken from the previous reports (Chen et al., 2010; Ban and Zhang, 2011). The process begins with the precipitation of chromium after the addition of sodium hydroxyde (if wastewater contains chromium), and then a general biologic waste water treatment including pre-treatment with the addition of ferrous sulfate and polyacrylamide in an aeration tank), secondary treatment and tertiary treatment, with microorganisms to reduce chemical oxygen demand (COD) and other pollution parameters.

\section{Results and discussions}

\subsection{Optimizations of wet-white tannage}

Fig. 4 comparatively shows the effect of types of vegetable tannins on the shrinkage temperature $\left(T_{\mathrm{s}}\right)$ of wet-white crust leathers. After solo tannic acid (TA) or mimosa tanning with the dosage of $15 \mathrm{wt} \%$, the $T_{\mathrm{s}}$ of the crust leather tanned by mimosa are obviously higher than TA. This is due to the fact that the astringency of condensed vegetable tannin like mimosa is stronger than that of hydrolysable tannin, TA (Covington, 1997). However, further addition of 4 wt\% Laponite nanoclay, the crust leathers tanned by the TA-Laponite combination show much higher $T_{\mathrm{s}}$ than those by mimosa-Laponite, as the tanning time prolongs. It is owing to the fact that TA has lower molecule weight $\left(M_{\mathrm{w}}\right)$ than mimosa, which can make it more possible to sufficiently penetrate into the leather matrix (Liao et al., 2003). The introduction of Laponite can facilitate the fixation of TA in the collagen fibers by the formation of hydrogen crosslinking between the phenolic hydroxyl groups of TA molecule and the active silanol groups on the surface site of Laponite nano-disk (Shi et al., 2016); whereas, the higher $M_{\mathrm{w}}$ and larger size of mimosa may block the diffusion of Laponite into collagen fibers. Therefore, the synergistic tanning effect of TA-Laponite is much more 
significant than mimosa-Laponite. Fig. 4 also indicates minor increase in $T_{\mathrm{s}}$ when the time of Laponite tanning is above $3 \mathrm{~h}$. Based on tanning effects and energy consumptions, the TA-Laponite combination tanning for $3 \mathrm{~h}$ is thus used for the following assessment.

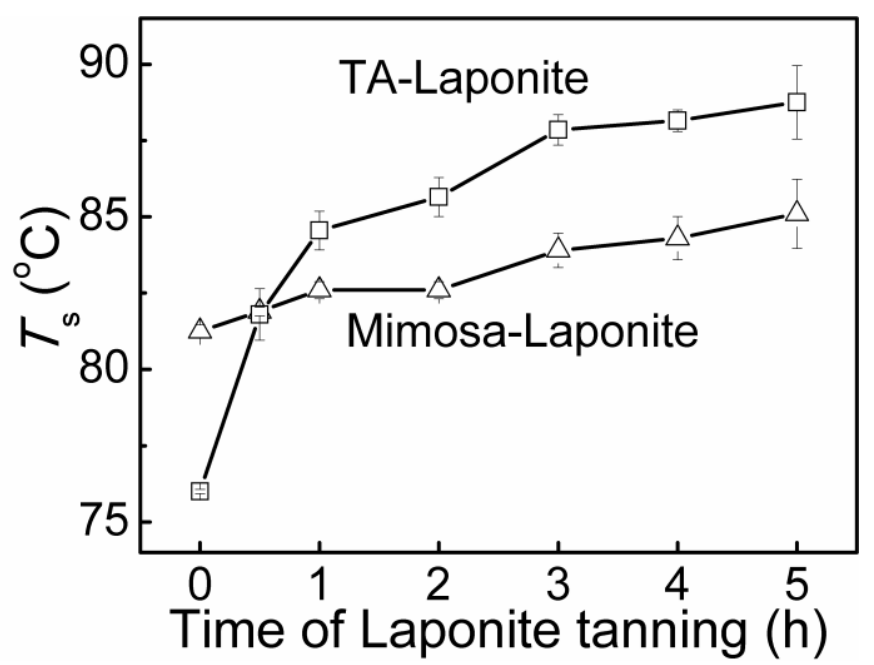

Fig. 4. $T_{\mathrm{s}}$ dependence of wet-white crust leathers on the Laponite tanning time in $15 \mathrm{wt} \%$ vegetable tannin combination tannage with $4 \mathrm{wt} \%$ Laponite

Fig. 5 shows that Laponite in the grain, middle and flesh layers are all $\sim 32.0 \mathrm{mg} / \mathrm{g}$, indicating its even penetration and binding in the wet-white crust leather. This can be owing to uniform dimensions of Laponite with a thickness of about $1 \mathrm{~nm}$ and a diameter of $25 \sim 30$ nm (Nicolai and Cocard, 2000) and good nano-dispersibility (Rao, 2007), which make it sufficient diffusion from outer float into collagen fiber networks (Gunter, 2007a).

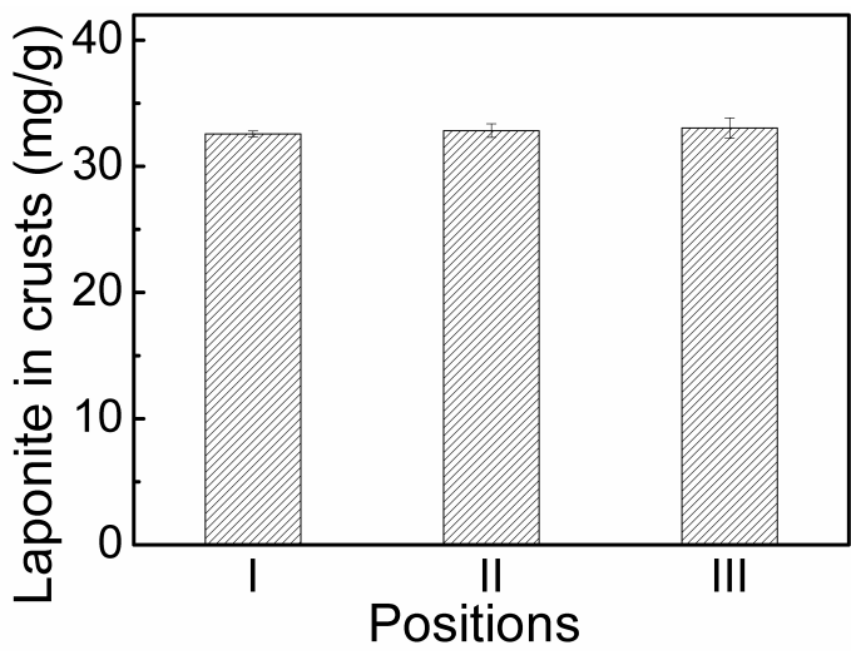

Fig. 5. The content of Laponite nanoclay in the TA-Laponite combination tanned crust leather: (I) grain 
layer, (II) middle layer and (III) flesh layer.

Fig. 6 presents $T_{\mathrm{s}}$ of the crusts in wet-white leather processing. Note that solo $15 \mathrm{wt} \% \mathrm{TA}$ tanning improves the $T_{\mathrm{s}}$ from $52.8 \pm 0.7{ }^{\circ} \mathrm{C}$ for the de-pickled pelt to $76.4 \pm 0.4{ }^{\circ} \mathrm{C}$. The obvious increase can be owing to hydrogen and hydrophobic bond associations between TA and collagen (Shi et al., 1994). As discussed above, after adding Laponite, $T_{\mathrm{s}}$ of the crusts rise above $86{ }^{\circ} \mathrm{C}$ because of the synergistic effects. In the subsequent retanning and fatiliquoring procedures, the resultant crusts exhibit $T_{\mathrm{s}}$ of $89.1 \pm 0.7{ }^{\circ} \mathrm{C}$ and $87.6 \pm 0.3{ }^{\circ} \mathrm{C}$, respectively, indicating that the stability of TA-Laponite combination tanning. Clearly, the $T_{\mathrm{s}}$ of the combination tanned crust leather can meet the requirements for next finishing procedures.

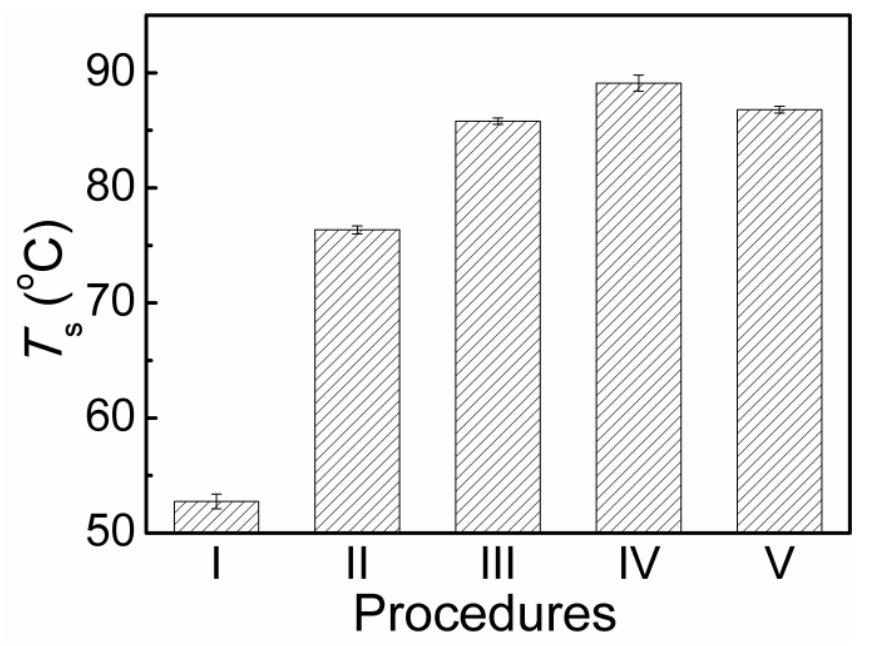

Fig. 6. $T_{\mathrm{s}}$ of the crusts in wet-white leather processing: (I) de-pickling, (II) TA tanning, (III) TA-Laponite combination tanning, (IV) retanning and (V) fatiliquoring.

\subsection{ICP analysis}

Fig. 7 gives the content of Laponite in the crusts (Fig. 7a) and floats (Fig. 7b), respectively, during the wet-white tanning process as measured by ICP technique. The binding capacity of Laponite in the tanned crust leather (Procedure II) is $32.45 \pm 1.60 \mathrm{mg} / \mathrm{g}$, i.e., 80\% of Laponite is fixed in the collagen fibers. It corresponds to the residual content is $1.73 \pm 0.05$ $\mathrm{mg} / \mathrm{L}$ Laponite in the tanning float. After retanning and fatiliquoring, some Laponite was 
washed out $(0.5 \sim 0.6 \mathrm{mg} / \mathrm{L}$ in the floats). This is reasonable because the fixation of tanning materials is known to be reversible under sustained exposure to water (Gunter, 2007b). However, more than $77 \%$ is still bound in the crusts to sufficiently maintain the hydrothermal stability.
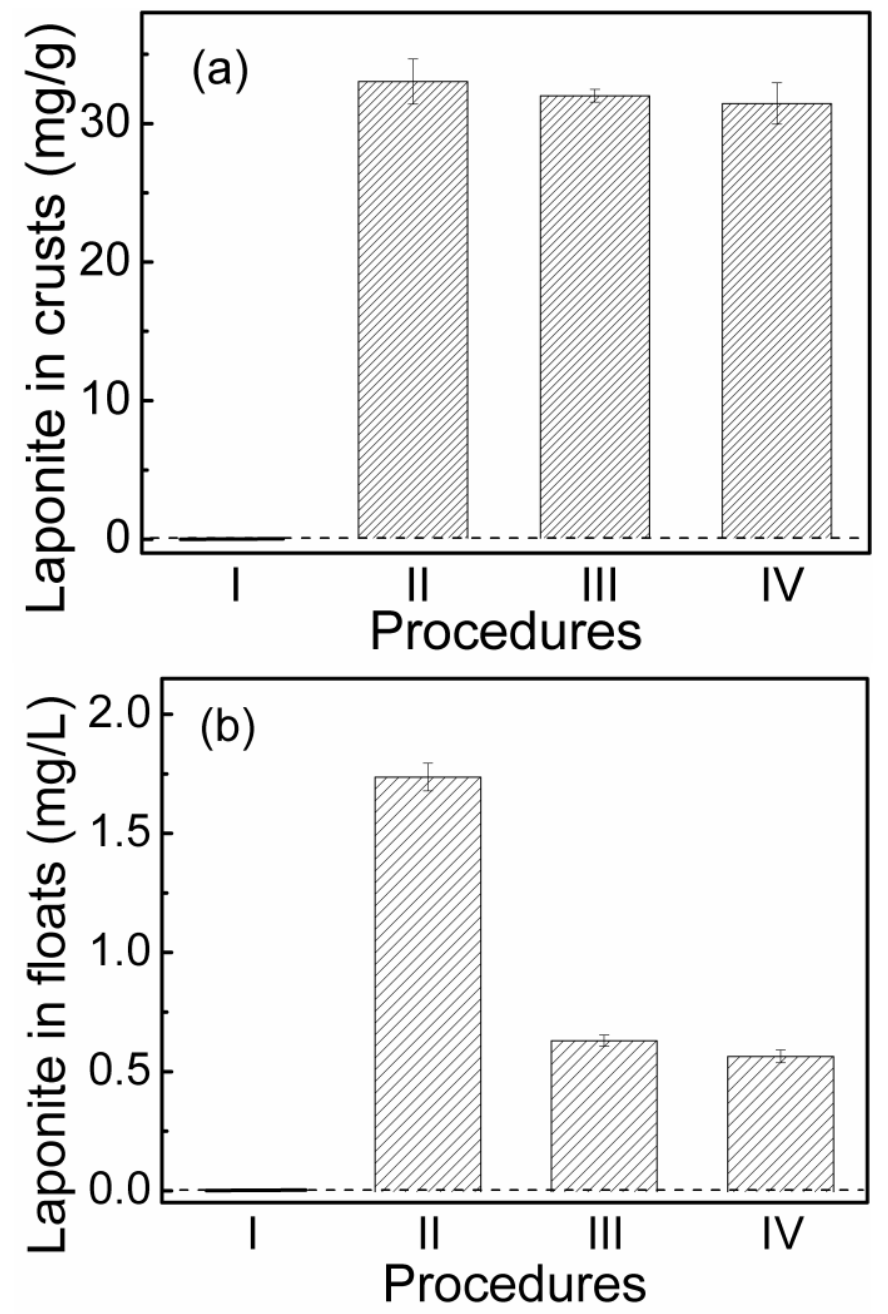

Fig. 7. The content of Laponite in the wet-white crust leather (a) and its residue (b) in the tanning float during the leather processing: (I) TA tanning, (II) TA-Laponite combination tanning, (III) retanning and (IV) fatiliquoring.

\subsection{SEM-EDX analysis}

Fig. 8 shows the microstructures of wet-white crust leather observed by scanning electron microscopy (SEM). Fig. 8a shows the grain layer of the leather, in which the hair pores are clearly visible without surface depositions of Laponite. The leather specimen in the 
middle and flesh layers also shows similar morphologies with an interwoven structure (Fig. $8 \mathrm{~b}, 8 \mathrm{c})$. Moreover, the elemental compositions in the corresponding positions of the leather matrix (pink areas in SEM images) have been analyzed by energy dispersive X-Ray (EDX) spectroscopy as shown in the insets. In the EDX spectra, magnesium $(\mathrm{Mg})$ and silicon $(\mathrm{Si})$, the feature elements of Laponite, show similar contents in the grain, middle and flesh layers, further demonstrating an even distribution of Laponite within the leather matrix. It can be expected that a reasonable good leather properties can be resulted.
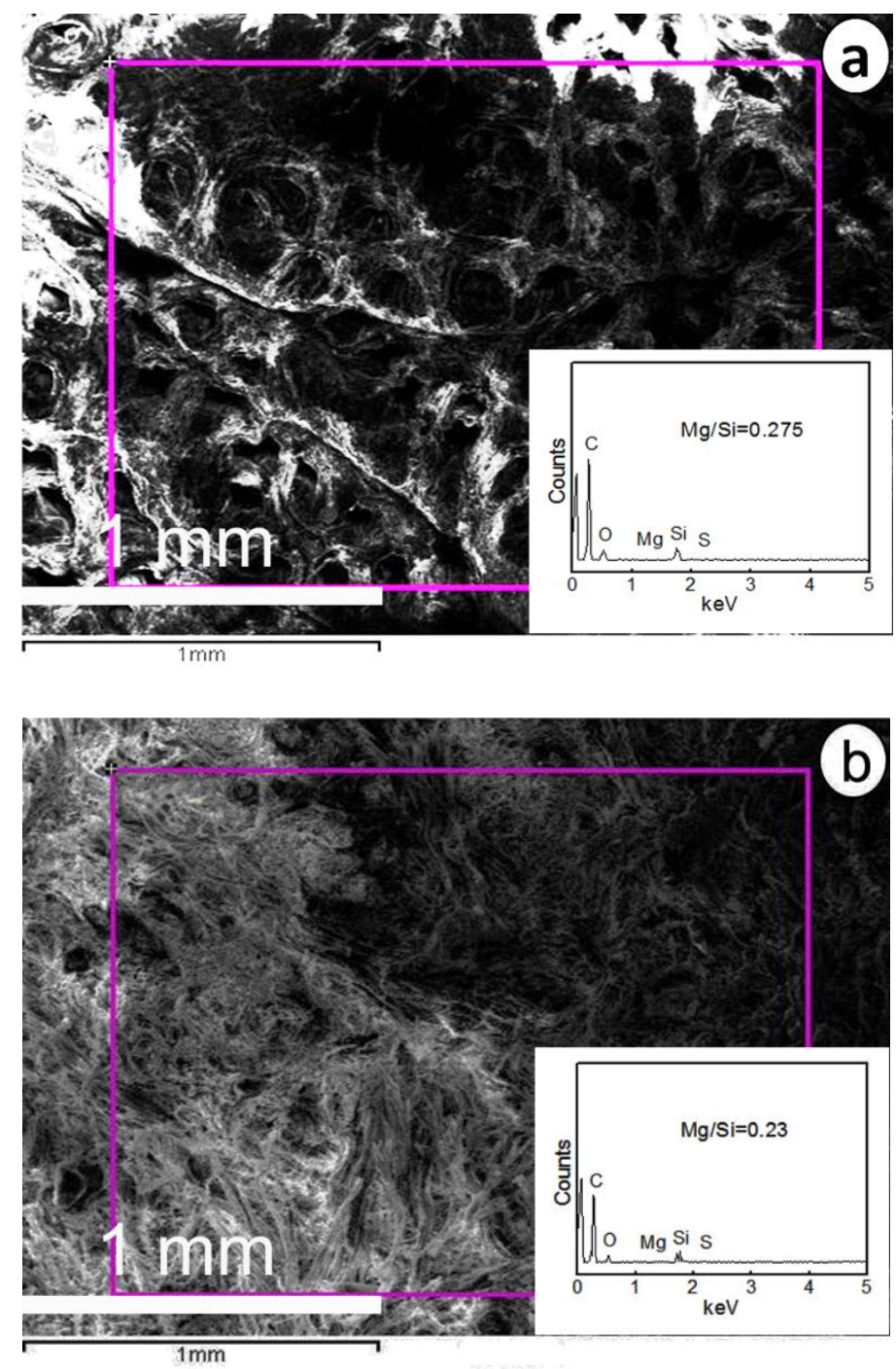


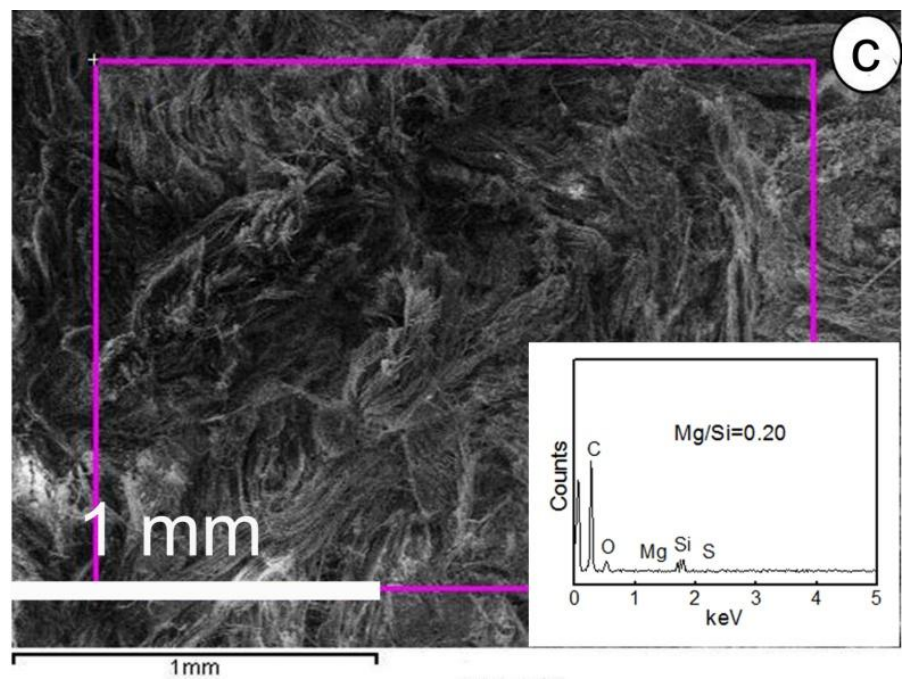

Fig. 8. SEM microphotographs and the corresponding EDX spectrums (the insets) of TA-Laponite combination tanned crust leather: (a) grain layer, (b) middle layer and (c) flesh layer.

\subsection{Physical performance measurements}

Table 3 presents physical properties of the wet-white crust leather and finished leather tested with the official methods recommended by IULTCS. It can be found that all of these physical properties can meet the Chinese standard requirements for furniture leather $(\mathrm{GB} / \mathrm{T}$ 16799-2008), indicating that the wet-white tannage can be applied in furniture leather manufacture.

\section{Table 3}

Physical properties of the wet-white crust leather and finished leather

\begin{tabular}{cccc}
\hline Physical properties & Crust & Finished leather & Norms \\
\hline Tensile strength (MPa) & $36.5 \pm 4.2$ & $43.6 \pm 2.5$ & - \\
Tear strength (N) & $81.9 \pm 3.0$ & $114.9 \pm 11.5$ & $\geq 40$ \\
Elongation at $10 \mathrm{~N}(\%)$ & $31.1 \pm 7.5$ & $32.3 \pm 7.2$ & - \\
Elongation at break (\%) & $48.5 \pm 6.5$ & $55.5 \pm 7.3$ & 35 \\
Flexing crack resistance & No cracking & No cracking & 20000 flexes with no cracks \\
\hline
\end{tabular}




\subsection{Hazardous substances results}

Table 4 lists the content of limited hazardous substances in the wet-white crust leather and finished leather. Both $\mathrm{Cr}(\mathrm{VI})$ and formaldehyde are not detected, showing that the leather products can meet the demands of the EU eco-label for footwear (2009/563/EC).

\section{Table 4}

The content of hazardous substances in the wet-white crust leather and finished leather

\begin{tabular}{cllc}
\hline Parameters & Crust & Finished leather & Limitations \\
\hline $\mathrm{Cr}(\mathrm{VI})(\mathrm{mg} / \mathrm{kg})$ & Not detected & Not detected & $3 \mathrm{mg} / \mathrm{kg}$ \\
Formaldehyde $(\mathrm{mg} / \mathrm{kg})$ & Not detected & Not detected & $20 \mathrm{mg} / \mathrm{kg}$ \\
\hline
\end{tabular}

* The limitations of the detection

\subsection{Environmental impacts assessment}

From the perspective of life cycle assessment (LCA), environmental impact categories of the wet-white tanning process were assessed through the CML 2001 methodology (revised on 2013). Fig. 9 gives the contribution of four factors to the impact categories. The results show that tanning is the main contributor to all impact categories except for marine aquatic ecotoxicity potential (MAETP) in which power (electricity production) is more significant. As to the substances in tanning process (Fig. 10), the most significant contributor for all impact categories is tanning agent, i.e. tannic acid, except for abiotic depletion potential (ADP).

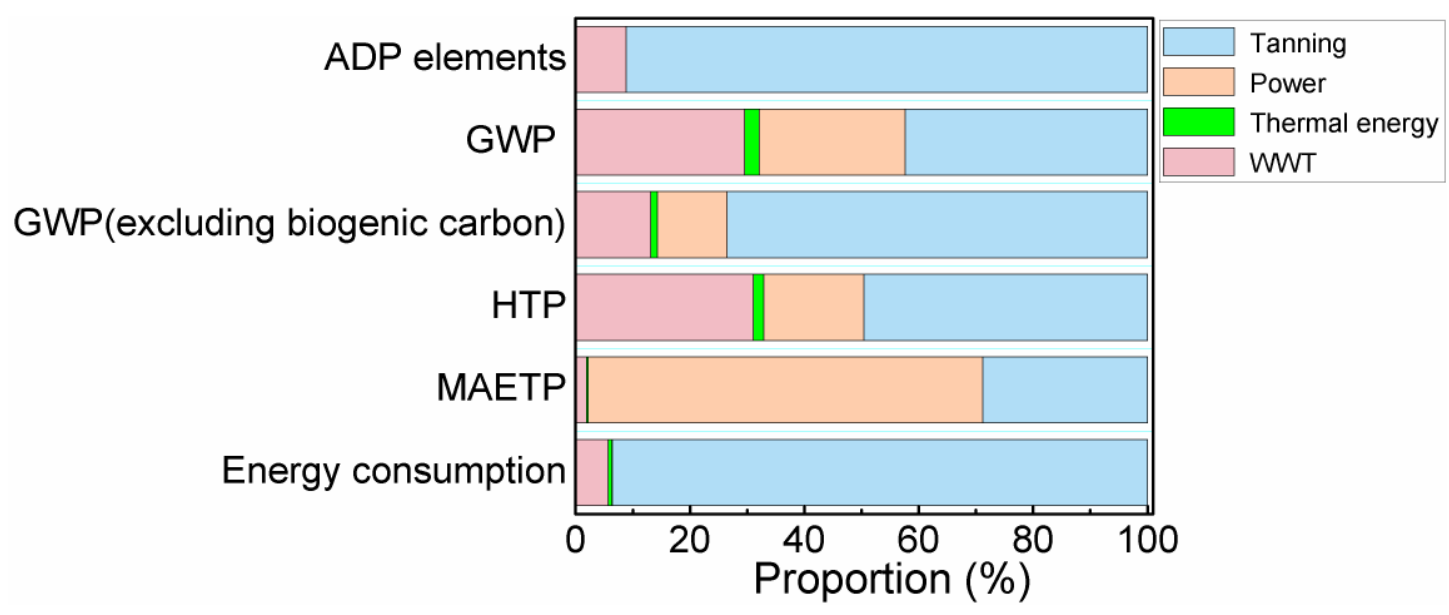


Fig. 9. Contribution of different life cycle stages of the wet-white tanning process to each impact category: abiotic depletion potential (ADP), global warming potential (GWP), global GWP excluding biogenic carbon, human toxicity potential (HTP), marine aquatic ecotoxicity potential (MAETP) and energy consumption.

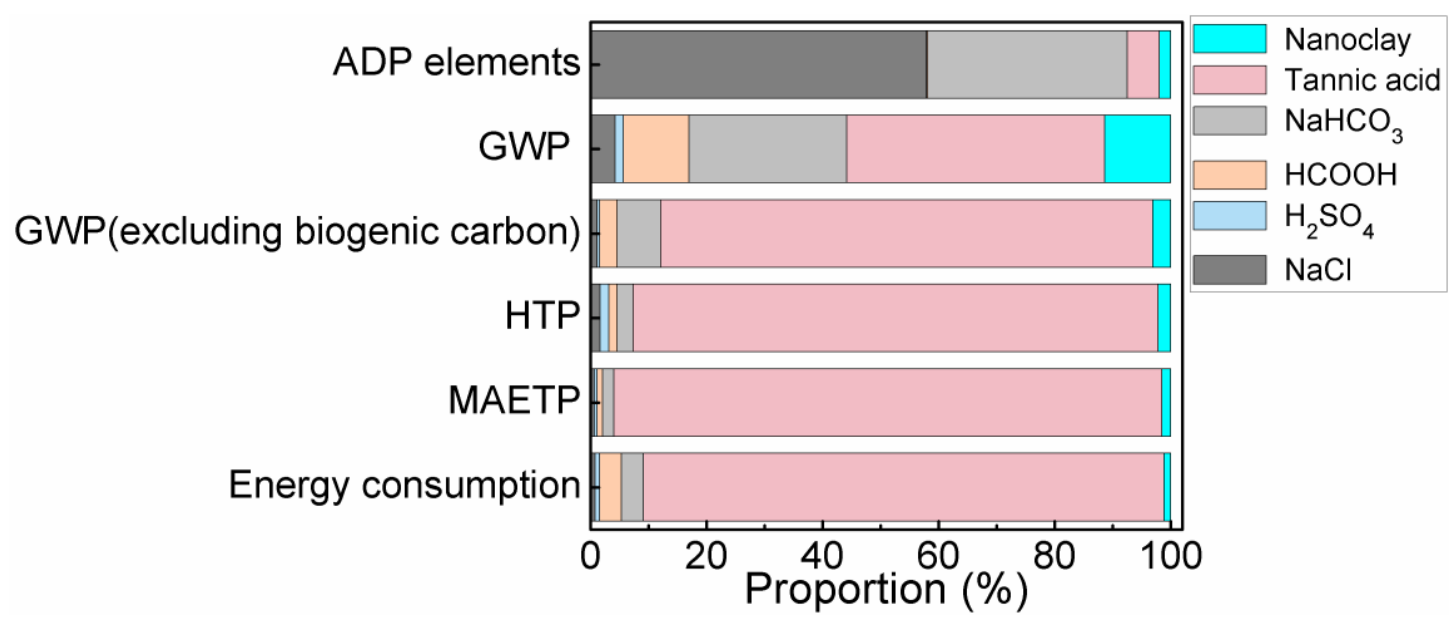

Fig. 10. Contribution of different chemicals used in the wet-white tanning process to each impact category: abiotic depletion potential (ADP), global warming potential (GWP), global GWP excluding biogenic carbon, human toxicity potential (HTP), marine aquatic ecotoxicity potential (MAETP) and energy consumption.

Fig. 11 comparatively shows the differences of environmental impact categories between wet-white and conventional chrome tanning process. As can be seen in Fig. 11a, the wet-white tanning process has much lower impact in ADP with reduction of $88.2 \%$, mainly due to the fact that chromium derivatives have a problem of abiotic resource depletion. Also, the wet-white tanning process performs better in global warming potential (GWP) impact (Fig. 11b) and the impact decreases from $463.2 \mathrm{~kg} \mathrm{CO}_{2}$ equivalent to $386.0 \mathrm{~kg} \mathrm{CO}_{2}$ equivalent by $16.7 \%$ than the conventional one. Moreover, the human toxicity potential (HTP) impact results (Fig. 11c) show a great preference for the novel wet-white tanning process by reducing a $28.2 \%$ compared to the conventional one. This reduction is mainly related to the decrease in the impact from WWT followed by the decrease in the tanning contributor owing to the 
absence of chromium, since TA tannin can be easily biodegraded with low toxicity and Laponite nanoclay does not show acute toxicity due to its nature of silicate (Field and Lettinga, 1992; Gaharwar et al., 2011).

However, other environmental impacts of the wet-white tanning process are not better than the conventional chrome tanning process. The GWP excluding biogenic carbon (Fig. 11d) results also show that tanning, energy consumption (power) and wastewater treatment (WWT) are higher in the wet-white tanning process due to the use of organic tanning materials. And energy consumption (Fig. 11e) is also much higher due to more tanning time requirements in the combination tanning. The results imply that the use of environmental friendly vegetable tannins is not always harmless to environment. Reducing the use of vegetable tanning material (or partially replace it with highly reactive mineral tanning agents), as well as decreasing electricity requirements, may mitigate these disadvantages. The LCA assessments on three typical tanning processes based on chrome, aldehyde and vegetable tannin have been previously reported by Ecobilan S.A. (BLC Leather Technology Centre Report 002). It was said that there is no fundamental difference in environmental impacts between these tanning technologies, and each tanning technology has strengths and weakness (BLC, 2013). Indeed, our LCA results reveal that the wet-white tanning process does not show absolute advantages in all the environmental impacts.

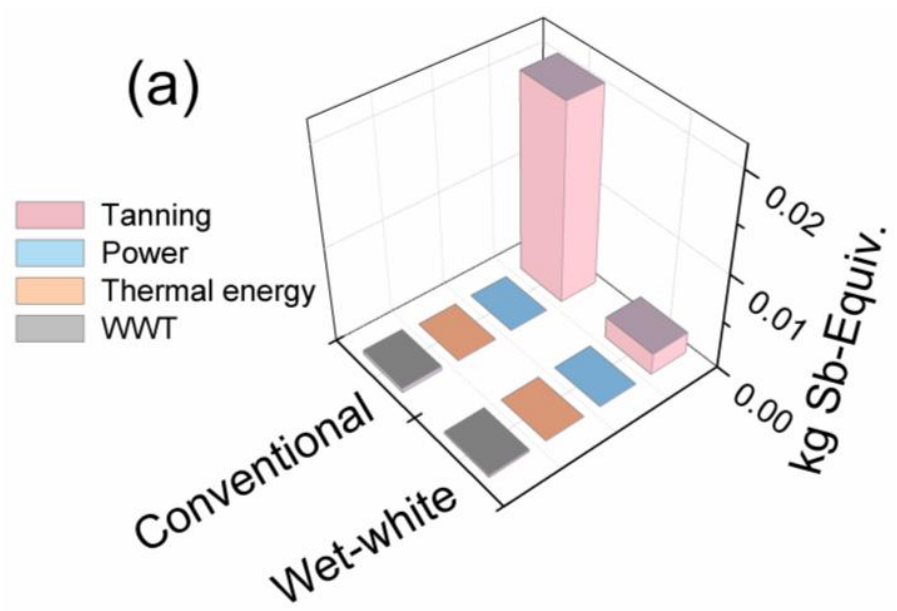



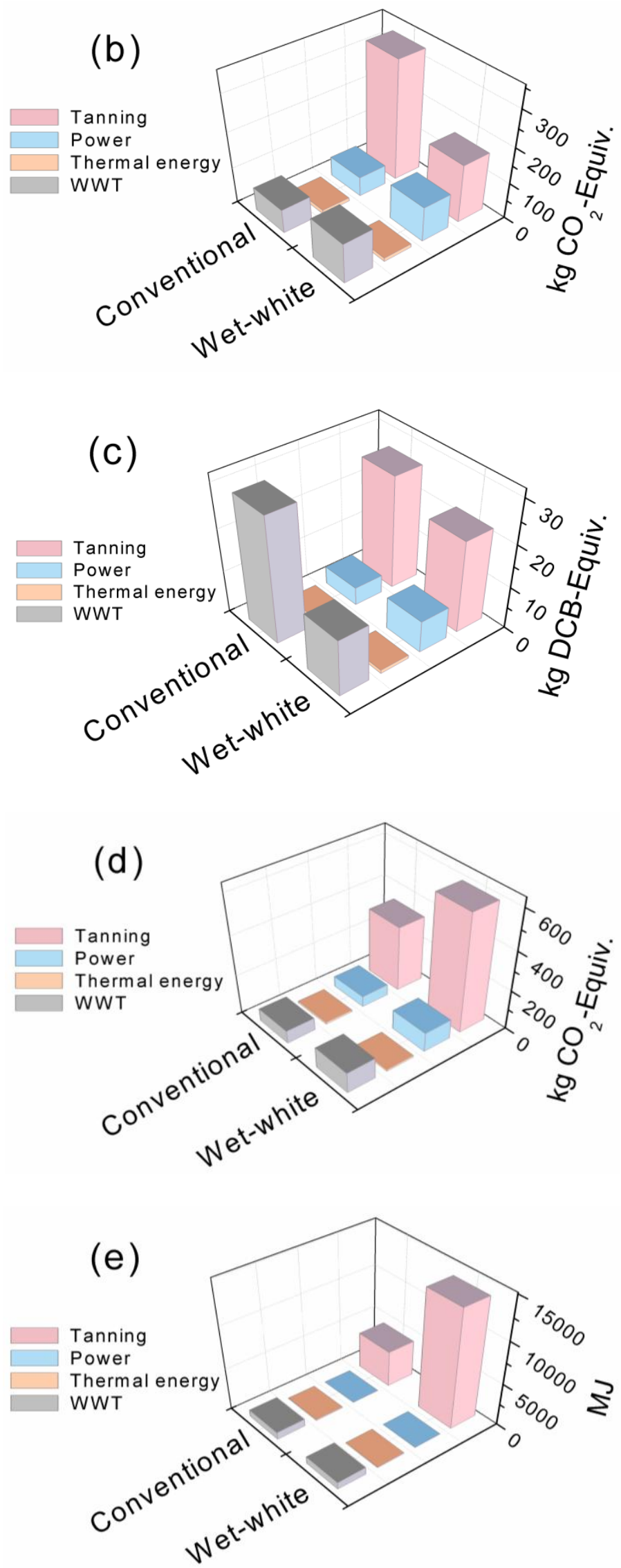

Fig. 11. Comparison between wet-white and conventional chrome tanning process: (a) abiotic depletion 
potential (ADP), (b) global warming potential (GWP), (c) human toxicity potential (HTP), (d) GWP excluding biogenic carbon and (e) energy consumption.

\section{Conclusions}

A novel wet-white leather manufacture based on vegetable tannin and Laponite nanoclay combination tannage has been established in this work. The $15 \mathrm{wt} \%$ tannic acid combination with 4 wt $\%$ Laponite tanning for $3 \mathrm{~h}$ can give the leather with $T_{\mathrm{s}}$ above $86{ }^{\circ} \mathrm{C}$. Laponite can penetrate evenly into leather matrix and bind tightly with collagen fibers. Moreover, the resultant leathers can meet the official standard requirements of physical properties for furniture leather, with no limited hazardous substances, $\mathrm{Cr}(\mathrm{VI})$ and free formaldehyde detected. LCA results indicate that tanning process is the main contributor to environmental impact categories. And the wet-white tanning process exhibits reduced environmental impacts in ADP, GWP and HTP impacts, but higher GWP impact excluding biogenic carbon and energy consumption than conventional chrome tanning. A reduction of both, vegetable tannin and electricity, consumptions would mitigate these disadvantages. The comprehensive evaluation on the leather properties and the environmental impacts from a novel tanning process is realistic and significant for the exploration of new tanning materials and the related process design.

\section{Acknowledgements}

The financial support of National Natural Science Foundation (NNSF) of China (21176159, 21476148), and National High-tech Research and Development Program (863 program) of China (2013AA06A306) is gratefully acknowledged. 


\section{References}

ASTM, 2004. Annual book of ASTM Standards. American Society for Testing \& Materials. 15-04, pp. 638-640.

Ban, F.C., Zhang, T., 2011. Design example of wastewater treatment plant of leather industry base. Technology of Water Treatment 37, 124-126.

Bridges, J., 2003. Human health and environmental risk assessment: the need for a more harmonised and integrated approach. Chemosphere 52, 1347-1351.

British Leather Center (BLC), 2013. Environmental impact of different tanning technologies.http://www.blcleathertech.com/blog/environmental-impact-of-different-tanning-t echnologies/2013/04/24/

Brunner, P.H., Rechberger, H., 2004. Practical handbook of material flow analysis. International Journal of Life Cycle Assessment 9, 337-338.

Burgess, A.A., Brennan, D.J., 2001. Application of life cycle assessment to chemical processes. Chemical Engineering Science 56, 2589-2604.

Chandra Babu, N.K., Asma, K., Raghupathi, A., Venba, R., Ramesh, R., Sadulla, S., 2005. Screening of leather auxiliaries for their role in toxic hexavalent chromium formation in leather-posing potential health hazards to the users. Journal of Cleaner Production 13, 1189-1195.

Chen Y.P., Tan J.L., Tang H.L., Lu T.L., Yang D.Q., 2010. Technical design and application analysis of tannery wastewater treatment. Biomass Chemical Engineering 44, 32-35.

Covington, A.D., 1997. Modern tanning chemistry. Chem. Soc. Rev. 26, 111-126.

Covington, A.D., 2009. Tanning chemistry: the science of leather. Royal Society of Chemistry, pp. 204-205.

Crudu, M., Deselnicu, V., Deselnicu, D.C., Albu, L., 2014. Valorization of titanium metal wastes as tanning agent used in leather industry. Waste Management 34, 1806-1814.

Erol, P., Thöming, J., 2005. ECO-design of reuse and recycling networks by multi-objective optimization. Journal of Cleaner Production 13, 1492-1503.

Field, J., Lettinga, G., 1992. Toxicity of tannic compounds to microorganisms. Plant polyphenols. Springer, pp. 673-692.

Gaharwar, A.K., Schexnailder, P.J., Kline, B.P., Schmidt, G., 2011. Assessment of using Laponite ${ }^{\circledR}$ cross-linked poly (ethylene oxide) for controlled cell adhesion and mineralization. Acta Biomaterialia 7, 568-577. 
Guinée, J.B., 2002. Handbook on life cycle assessment operational guide to the ISO standards. The International Journal of Life Cycle Assessment 7, 311-313.

Gunter, R., 2007a. From collagen to leather - the theoretical background. BASF service center media and communications, Ludwigshafen, pp. 42-45.

Gunter, R., 2007b. From collagen to leather - the theoretical background. BASF service center media and communications, Ludwigshafen, p. 47.

Hansen, M., Johansen, J., Menne, T., 2003. Chromium allergy: significance of both Cr(III) and Cr(VI). Contact Dermatitis 49, 206-212.

Jacquemin, L., Pontalier, P.Y., Sablayrolles, C., 2012. Life cycle assessment (LCA) applied to the process industry: a review. International Journal of Life Cycle Assessment 17, 1028-1041. Jay, S., Jones, C., Slinn, P., Wood, C., 2007. Environmental impact assessment: Retrospect and prospect. Environmental Impact Assessment Review 27, 287-300.

Krishnamoorthy, G., Sadulla, S., Sehgal, P.K., Mandal, A.B., 2013. Greener approach to leather tanning process: D-Lysine aldehyde as novel tanning agent for chrome-free tanning. Journal of Cleaner Production 42, 277-286.

Liao, X.P., Lu, Z.B., Shi, B., 2003. Selective adsorption of vegetable tannins onto collagen fibers. Industrial \& Engineering Chemistry Research 42, 3397-3402.

Liu, Y.S., Chen, Y., Yao, J., Fan, H.J., Shi, B., Peng, B.Y., 2010. An environmentally friendly leather-making process based on silica chemistry. J. Am. Leather Chem. Assoc. 105, 84-93.

Metreveli, G., Kaulisch, E.M., Frimmel, F.H., 2005. Coupling of a column system with ICP-MS for the characterisation of colloid-mediated metal (loid) transport in porous media. Acta Hydrochimica Et Hydrobiologica 33, 337-345.

Nicolai, T., Cocard, S., 2000. Light scattering study of the dispersion of laponite. Langmuir $16,8189-8193$.

Pourzahedi, L., Eckelman, M.J., 2015. Environmental life cycle assessment of nanosilver-enabled bandages. Environmental science \& technology 49, 361-368.

Rao, Y., 2007. Gelatin-clay nanocomposites of improved properties. Polymer 48, 5369-5375.

Shen, L., Patel, M.K., 2008. Life cycle assessment of polysaccharide materials: A review. Journal of Polymers \& the Environment 16, 154-167.

Shi, B., He, X., Haslam, E., 1994. Gelatin-polyphenol interaction. J. Am. Leather Chem. Assoc. 89, 96-102.

Shi, J.B., Ren, K.S., Wang, C.H., Wang, J., Lin, W., 2016. A novel approach for wet-white leather manufacture based on tannic acid-Laponite nanoclay combination tannage. J. Soc. Leather Technol. Chem. 100, 25-30. 
Shi, J.B., Zhou, Y.L., Li, X.P., Lin, W., 2013. A novel combination tanning based on tannic acid and attapulgite nanoclay. China Leather 3, 1-5.

Silvestre, J.D., de Brito, J., Pinheiro, M.D., 2014. Environmental impacts and benefits of the end-of-life of building materials - calculation rules, results and contribution to a "cradle to cradle" life cycle. Journal of Cleaner Production 66, 37-45.

Tukker, A., 2000. Life cycle assessment as a tool in environmental impact assessment. Environmental Impact Assessment Review 20, 435-456.

Wang, Y.N., Zeng, Y.H., Zhou, J.F., Zhang, W.H., Liao, X.P., Shi, B., 2016. An integrated cleaner beamhouse process for minimization of nitrogen pollution in leather manufacture. Journal of Cleaner Production 112, 2-8.

Xu, X.Y., Baquero, G., Puig, R., Shi, J.B., Sang, J., Lin, W., 2015. Carbon footprint and toxicity indicators of alternative chromium-free tanning in China. J. Am. Leather Chem. Assoc. 110, 130-137.

Zhang, C.X., Lin, J., Jia, X.J., Peng, B.Y., 2016. A salt-free and chromium discharge minimizing tanning technology: the novel cleaner integrated chrome tanning process. Journal of Cleaner Production 112, 1055-1063. 